\title{
Note from the Editors
}

The present issue, the second one published under the current editorial team, begins the $7^{\text {th }}$ volume of the Nordic Wittgenstein Review. We received a considerable number of submissions for this issue, which means that we, in addition to relying on our trustworthy pool of reviewers, have also had to try to solicit new referees. We are very happy that so many accepted our invitation and agreed to use their time and resources on this rather unacknowledged task. We want to thank everybody who participated in the review process for their unselfish and conscientious work, which has made it possible to keep up the double blind peer review procedure that is so important for the quality of the journal. From the feedback we have received, we also know that the work of our referees is often highly appreciated by the authors of the submissions. From the next issue, we are in addition hoping to re-introduce the Preprint Open Review procedure, in which accepted papers are posted online some time before proper publication, available for comments.

We always welcome the response and criticisms of our readers. While the content of this feedback has been overwhelmingly positive and encouraging, two causes of complaint tend to recur: firstly, there seems to be a certain dissatisfaction with both the aesthetics and functionality of our current website. Since our ambition is to be a truly open access journal, it is natural that we have also opted for a free source code software solution, in this case the Open Journal System. OJS is an open-source software for the management of peerreviewed academic journals, created by the Public Knowledge Project, and released under the GNU General Public License. Even if we are generally happy with this solution, the software has suffered from its share of child-diseases, especially in connection with major upgrades. And as with all open source software, solutions to specific problems often have to wait until one is found and published by the user community. However, we expect that the journal system continues to improve, and are hopeful that current inconveniences will eventually disappear (without being replaced by new ones). When it comes to our admittedly frugal graphical profile, we are 
planning an upgrade. One of the advantages of the OJS software is that it gives great freedom for the journals using it to implement individual graphical solutions for their user interface. We hope that we in the not-too-distant future can introduce a both functionally and aesthetically more pleasing website.

A second source of dissatisfaction among readers has been the lack of a print version of the journal. NWR has not been issued in print since we (from Volume 4) decided to go fully open access with the Nordic Wittgenstein Society as publisher. However, the plan was already then to make the journal available also in print. It has proved more difficult than expected to find a solution that combines reasonable price, good quality and availability, but we do hope that we can soon offer a possibility to purchase back copies of the journal, preferably through some kind of print on demand solution.

Meanwhile, NWR is published online as usual with two issues per year. The next ordinary issue will appear in December (deadline for submissions is 31 August). In addition, we are happy to announce the second ever special issue of the NWR, on the theme of "PostTruth", guest edited by Rupert Read and Timur Uçan. This timely issue is scheduled for publication in the fall of 2018.

The sad news of Stanley Cavell's death reached us while we were putting the finishing touches on this text. It is difficult to overestimate the importance and influence of his readings of Wittgenstein, which were the result of a lifelong intense engagement with this philosopher. First and foremost, however, Cavell will be remembered as one of the few truly original voices in contemporary philosophy. The best tribute to him that we can think of is to try to let our work with this journal be inspired by the generous and inclusive philosophical spirit that is a hallmark of his work.

Bergen-Uppsala

June 2018

The editors

Simo Säätelä, Gisela Bengtsson \& Tove Österman 